\title{
O utilitarismo de assalto às ciências da educação
}

\section{Assaulting utilitarianism against education sciences}

\section{L'utilitarisme à l'assaut des sciences de l'éducation}

\author{
Yves Lenoir ${ }^{1}$
}

\begin{abstract}
RESUMO
Este texto refere-se à tradução de um artigo inicialmente publicado numa versão reduzida “Quem quer a morte das ciências da educação?” (MEIRIEU et al., 2014). O texto trata das finalidades das ciências da educação e do seu desvirtuamento em função de valores utilitaristas. Nele é explicado que o utilitarismo remete à busca de interesses individuais que enfatizam a dimensão econômica como único vetor do comportamento humano e que sua difusão prioriza valores mercantis que chegam às universidades desvirtuando-as de suas finalidades humanas e sociais.
\end{abstract}

Palavras-chave: ciências da educação; finalidades educacionais; utilitarismo; mercantilização da educação.

DOI: $10.1590 / 0104-4060.47109$

1 Titular da Cátedra de Pesquisa do Canadá sobre Intervenção Educativa (Chaire de Recherche du Canada sur l'Intervention Éducative - CRCIE), da Faculdade de Educação da Universidade de Sherbrooke, na província do Quebec. Texto original publicado em língua francesa, disponível em: $<$ http://www.usherbrooke.ca/crcie/fileadmin/sites/crcie/fichiers/Bulletin/Bulletin-6-VF-4.pdf $>$.

Tradução: Renata Luiza da Costa. Instituto Federal de Goiás. Inhumas, Goiás, Brasil. Campus Inhumas. Avenida Universitária, s/nº Quadra Única. Vale das Goiabeiras. CEP: 75.400-000. E-mail: rldcosta@gmail.com; rldcosta@ifg.edu.br

José Carlos Libâneo. Pontifícia Universidade Católica de Goiás. Programa de Pós-Graduação em Educação. Goiânia, Goiás, Brasil. Av. Universitária, nº 1.440. Setor Universitário. CEP: 74.605010.E-mail: libaneojc@uol.com.br 


\begin{abstract}
This text was first published in a reduced version, "Who wants the death of education sciences?" (MEIRIEU et al., 2014). Here, it was revised and enriched. The text deals with the purposes of education sciences and its distortion due to utilitarian values. It is explained that utilitarianism refers to the pursuit of individual interests that emphasize the economic dimension as the only vector of human behavior and its diffusion prioritize market values that reach the universities depreciating them on their human and social aims.

Keywords: education sciences; educational aims; utilitarianism; educational mercantilism.
\end{abstract}

\title{
RÉSUMÉ
}

Ce texte, qui a été révisé et enrichi, a été initialement publié dans une version très réduite dans: Qui veut la mort des sciences de l'éducation? (MEIRIEU et al., 2014). Il aborde les objectifs de la science d'education et de sa déformation due aux valeurs utilitaristes. Il explique que l'utilitarisme fait référence à la poursuite des intérêts individuels qui mettent l'accent sur la dimension économique comme le seul vecteur du comportement humain et la diffusion de ces valeurs donnent la priorité aux principes du marché atteignant les universités entraînant une dépréciation de leurs but humains et sociaux.

Mots clés: sciences de l'éducation; fins éducatives; utilitarisme; marchandisation de l'éducation.

Num debate que se realizava no Quebec, há alguns anos, sobre a pertinência da área da educação na universidade, um participante declarou que as "ciências da educação custam caro!". Dizia que elas eram, como muitas formações universitárias, um tanto inúteis, improdutivas, em resumo, absolutamente vazias. "Isto é verdade na mente de muitos gestores, políticos e outros, concluiu ele, mas, acrescentou ironicamente, experimente a ignorância para ver...". Realmente, como na fábula de La Fontaine, ele constatou que um mal se espalha pelo mundo ocidental nas últimas décadas como um incêndio. Esse mal tem um nome: utilitarismo! Assim como há uma grande diferença entre individualização e individualismo ou entre cultura e culturalismo, não podemos confundir utilidade e utilitarismo. Se todos os seres humanos buscam que seus atos sejam úteis sob diversos aspectos (econômico, mas também político, cultural, social, etc.) como tem mostrado Caillé (2003, 2009), Caillé, Lazzeri e Senellart (2001) e Freitag (2011), o utilitarismo, por sua parte, remete à busca 
do interesse individual e egoísta, a dimensão econômica tornando-se o único vetor do comportamento do humano.

Em suma, a concepção empirista, sensualista e utilitarista de realidade humana não guarda a não ser o valor mercantil da vida, respondendo aos interesses individuais e imediatos dos seres humanos. Se os modelos científico e liberal de universidade (DRÈZE; DEBELLE, 1968; LESSARD; TARDIF, 2006) e, mais amplamente, os sistemas de ensino ditos tradicionais carregam uma opção elitista forte - ninguém discordaria disso -, é preciso se perguntar se o modelo de Universidade de excelência (READINGS, 1996) e a escola utilitarista não estariam trazendo com eles os fundamentos de processos de exclusão e de alienação sociais. Se o fenômeno for invertido, o resultado não muda, senão para pior. Podemos conceber o ser humano como um mero elemento de um conjunto, um ator isolado tendo por motivos o interesse instrumental como únicas perspectivas humanas e sociais de relações utilitárias do tipo mercantil? Observemos aqui que Caillé (2009) e outros, tais como Caillé, Lazzeri e Senellart (2001), criticaram esta concepção individualista de ser humano e mostraram que existe uma alternativa não utilitarista baseada na teoria de reconhecimento, sobre um conjunto de princípios que colocam o ser humano como um ser coletivo que só existe nas suas relações sociais com o outro, o que Hegel teorizou claramente no início do século XIX.

Nessa lógica utilitarista, que cruzou novamente o Atlântico para fazer um segundo ninho na Europa, após ter encontrado sua origem na Escócia dos séculos XVII e XVIII (Davi Hume, empirismo radical), uma "boa governança", que deve assegurar a gestão da formação do "capital humano", não pode senão fazer apelo aos princípios da eficiência, da eficácia, da produtividade, da competitividade, do desempenho, da flexibilidade, da desregulamentação, etc., palavras de ordem essenciais a um pensamento empreendedor que invadiu os sistemas educativos ocidentais, incluindo também universidades. Assim, no plano educativo, na França, no lugar da lógica republicana que se apoiava no humanismo e no universalismo transcendental que emana do Renascimento, dos filósofos do século XVIII e da Enciclopédia, e que defendia uma educação de caráter emancipador fundada sobre a aquisição de um saber vindo de disciplinas científicas, saber sustentado pela razão, tal como em países anglo-saxões, as universidades francófonas se veem levadas pelo turbilhão da globalização neoliberal que finaliza o instrumento, isto é, o processo educativo - e instrumentaliza a finalidade, isto é, a insere no mercado e suas "leis", desviando-o de suas finalidades humanas e sociais.

Deveríamos, então, pensar como Wilshire (1990) sobre o colapso moral da universidade, quando a universidade moderna alemã de século XIX havia colocado a educação moral no núcleo de suas responsabilidades? Ou como 
Freitag (1995), em relação ao naufrágio de uma universidade que perdeu suas referências culturais e intelectuais não tendo como motor e horizonte a não ser o fazer procedimental, ocultando e excluindo as capacidades de pensar, produzir e refletir vindas da cultura? Como Readings (1996), em relação à universidade de excelência que está muito mais para desmoronar? Como Tudiver (1999), para quem as universidades canadenses estão à venda a quem oferecer mais? Ou, ainda, como Aronowitz (2000), para quem é urgente desmantelar esta fábrica de saberes que tem se transformado a universidade empresarial?

Em qualquer caso, é incontestável que as universidades ocidentais têm se curvado às exigências da comercialização do saber, sejam quais forem os perigos. (TURK, 2000). Poderíamos pensar que o neoliberalismo triunfante, que põe fim ao Estado tutelar (JOBERT, 1995) e, também, ao Estado de Bem-Estar, levaria a um retorno ao Estado liberal. Uma interpretação como esta poderia se impor como uma evidência em favor da redescoberta das virtudes do mercado autorregulador, dos benefícios da livre iniciativa, da promoção da iniciativa pessoal, da responsabilização dos atores sociais. Nós devemos estar bem conscientes, a este respeito, do fato de que a orientação economicista que domina hoje num neocapitalismo sempre triunfante foi apreendida como um processo emancipador no século XVII por meio da teoria do individualismo possessivo posto em destaque de Hobbes a Locke (MACPHERSON, 2004), teoria essa fundada sobre a liberdade de comércio e sobre o direito à propriedade privada que afirmava a primazia emergente da esfera econômica na vida social. Como sublinha Delmotte (2013, p. 110), “[...] este tipo individualista de emancipação a respeito da ordem social tradicional não é certamente sinônimo de democracia", pelo fato que ele considera os seres humanos como átomos isolados essencialmente egoístas e que ele não se destina a não ser às classes privilegiadas da sociedade, os detentores da terra e dos bens de produção.

É por isso que essa interpretação de uma forma histórica agora retomada (o individualismo na perspectiva liberal) se mostra tão ingênua quanto errônea, a história não é nunca circular. A crença nisso arriscaria a levar os universitários em geral, os pesquisadores em educação em particular, a becos sem saída em matéria de investigação e compreensão dos fenômenos estudados. A crença nisso levaria a tomar os discursos ideológicos legitimadores por descrições válidas e fundadas da realidade humana e social. A crença nisso testemunharia uma recusa em ampliar a busca da compreensão das características e dos problemas do sistema escolar do século XXI. Porque não podemos permanecer nesses discursos que, mesmo quando defendem a virtude, não deixam de ser profundamente marcados ideologicamente e politicamente. A crença nisso seria a prova de um cegamento voluntário ou de uma incompetência notória. Devemos, ao contrário, buscar decifrar as influências ontológicas, teleológicas 
e praxiológicas que estão na origem dessas evoluções, retraçando a gênese e a dinâmica sócio-histórica².

As perspectivas econômicas implementadas atualmente pelas organizações, incluindo a universidade, a qual abandonou um modelo institucional para adotar um modelo organizacional, ignoram, portanto, sistematicamente os custos sociais das políticas implementadas e, também, os danos em longo prazo, hoje amplamente documentados (BAUMAN, 2000; DUBET, 2004; EHRENBERG, 2000, 2012; HONNETH, 2006; LENOIR, 2012; MARZANO, 2008; MONZEE, 2010; RENAULT, 2004; STIGLITZ, 2002, 2006), suscitados tanto na vida cotidiana dos seres humanos quanto na vida intelectual das sociedades. Numa educação utilitarista que prospera, centrada numa função de aculturação para uma economia de mercado, o princípio do humanismo foi substituído por aquele do profissionalismo, que os estadunidenses chamaram no fim do século XIX de "vocacionalismo" (no sentido de vocação profissional). Os sistemas de ensino atuais são administrados como "empresas de serviços", de mercantilização do saber, que devem funcionar de acordo com as "regras" econômicas do mercado. A função da instituição escolar é transformada para substituir uma democracia de consumidores por uma democracia de cidadãos, estes reduzidos a indivíduos isolados e egoístas interessados somente no seu próprio conforto econômico. Em outras palavras, a tendência forte que emerge e que defende esta orientação conduz numerosos alunos a irem à universidade para obter um diploma que lhes permita "vencer na vida" e não para estudar, desenvolver as suas capacidades intelectuais e "ter sua vida bem-sucedida": "eu pago, em troca me deem o "Vade mecum'3 que garantirá meu sucesso na vida profissional!".

Se não rejeitamos de modo algum a profissionalização, o que no campo da educação acontece na França com as Escolas Superiores de formação de Professores e de Educação (ESPE) - antigo IUFM -, parece legítimo nos preocuparmos profundamente com as decisões que levam à eliminação da formação

2 Numa obra em preparação sobre finalidades educativas escolares, sublinharemos em um dos capítulos, nos apoiando em trabalhos principalmente de Freitag (2011), a existência de duas rupturas fundamentais que influenciaram profundamente as escolhas socioeducativas ocidentais e a interação conflitante entre quatro fundamentos sociofilosóficos que têm marcado profundamente o pensamento ocidental e, desse modo, os sistemas educativos escolares, e que desembocam numa denominação hegemônica de utilitarismo individualista. Referência do livro mencionado: LENOIR, Y.; ADIGÜZEL, O.; LENOIR, A.; LIBÂNEO, J. C.; TUPIN, F. (Dir.). Les finalités éducatives scolaires: une étude critique des approches théoriques, philosophiques et idéologiques. Fondements, notions et enjeux socioéducatifs. Préface de Christian Laval. Groupéditions Éditeurs - Bibliothèque et Archives nationales du Québec, 2016. (Collection Cursus universitaire, Tome 1).

3 "Vade mecum" é uma expressão latina (significa "vai comigo") para designar um compêndio de conhecimentos básicos numa área que pode ser consultado facilmente. É de uso comum no direito e na medicina (NT). 
universitária, hoje as ciências da educação, amanhã muito possivelmente outros campos disciplinares considerados improdutivos e irrelevantes. Tal escolha, que é dramática, não é inocente. Ela baseia-se na concepção utilitarista que vimos descrevendo. O que é, então, banido da universidade, é a concepção mesma de universidade, quer dizer, a ideia de um suporte reflexivo de um ideal civilizatório à orientação universalista que requer a transmissão crítica das conquistas essenciais do passado e síntese rigorosa dos novos saberes que ela produziu a fim de pensar o que está por vir.

Assim como o pensamento de senso comum e a concepção utilitarista estimam que a teoria - dizemos igualmente a conceitualização - não é "prática", alguns consideram que as ciências da educação são sem valor, sem utilidade instrumental. Eles se apoiam nesta tendência que não considera a formação e a pesquisa a não ser pelo critério único dos seus impactos e de sua eficiência nas práticas, visão tão fragmentada quanto redutora que, obcecada pelas dimensões empíricas e, sobretudo, operatórias, refuta a necessidade de conceitualizar a realidade, como se esta pudesse ser revelada imediatamente apenas com um olhar de observador.

E ainda! O que haveria de mais útil do que poder entender as orientações, as questões, os desafios, as tendências, as contradições que movimentam o mundo da educação? Alguns dirão de novo que este trabalho de compreensão importa exclusivamente às disciplinas científicas. Isto se refere a uma visão purista e quimérica da ciência que resiste a quaisquer alianças (ou alianças ruins) e cuja onipotência intrínseca seria capaz de compreender a complexidade da realidade humana e social. Este tempo da ilusão de purificação althusseriana (ALTHUSSER, 1974) de livrar a ciência de toda escória metafísica, política e ideológica está ultrapassado. Ao contrário, as ciências da educação requerem precisamente uma visão pluridisciplinar, senão interdisciplinar, que é uma pedra angular essencial que lhes permite lutar com os discursos ideológicos, políticos, econômicos que atravessam o mundo da educação e casam de maneira coerente a filosofia, psicologia, sociologia, história da educação, metodologia, ciências políticas e econômicas, etc., o que fornece a possibilidade de identificar problemas sociais complexos retomando seus fundamentos.

Se o utilitarismo movimenta o pensamento e dita as escolhas de muitos dirigentes, seria possível, além disso, que outro fator interagisse com ele, mesmo se, à primeira vista, pudesse parecer pouco compatível: à adesão ao utilitarismo se associaria talvez uma alergia a essa pluridisciplinaridade vinda do fundo supremacista que caracteriza algumas disciplinas e que torna insuportável qualquer relação efetiva entre disciplinas. Seja como for, as ciências da educação constituem um campo pluri-inter-disciplinar autônomo e insubstituível que tem por função produzir saberes específicos sobre esta realidade altamente complexa, 
fazendo apelo ao cruzamento de disciplinas científicas, estas últimas não sendo capazes por elas mesmas de apreender sua complexidade. Excluí-las da formação universitária do primeiro ciclo (graduação) é dificultar o prosseguimento de estudos superiores no campo. É igualmente levar à cegueira todos aqueles que, na universidade e fora dela, se debruçam sobre suas múltiplas facetas, pois a função primeira das ciências da educação é considerar de maneira crítica e distanciada a relação estreita que existe entre as funções empírica e operacional, fazendo da teoria a mediação central, essencial e indispensável entre estas duas funções para dar-lhes um sentido. (LENOIR, 2014). Elas se distinguem, então, muito claramente da formação de professores que, de um ponto de vista mais prescritivo e preocupado com a eficiência, centra-se sobre as funções empírica e operacional, apelando para a necessidade da função teórica. Neste sentido, cabe às ciências da educação alimentar a formação de professores pela iluminação teórica que elas produzem. Ainda é preciso usá-las e a elas recorrer, submetê-las ao flagelo da investigação rigorosa e as ensinar...

\section{REFERÊNCIAS}

ALTHUSSER, L. Philosophie et philosophie spontanée des savants (1967). Paris: François Maspéro, 1974.

ARONOWITZ, S. Knowledge factory. Dismantling the corporate university and creating true higher learning. Boston: Bacon Press, 2000.

BAUMAN, Z. Liquid modernity. Cambridge: Polity Press, 2000.

CAILlE, A. Critique de la raison utilitaire. Manifeste du MAUSS. Paris: La Découverte, 2003.

CAILLE, A. Théorie anti-utilitariste de l'action. Fragments d'une sociologie générale. Paris: Éditions La Découverte, 2009.

CAILlE, A.; LAZZERI, C.; SENELLART, M. (Dir.). Histoire raisonnée de la philosophie morale et politique. Le bonheur et l'utile. Paris: Éditions La Découverte, 2001.

DELMOTTE, F. Les ambiguïtés de l'émancipation et le projet révolutionnaire démocratique. In: CUKIER, A.; DELMOTTE, F.; LAVERGNE, C. (Dir.). Émancipation, les métamorphoses de la critique sociale. Bellecombe-en-Bauges: Éditions du Croquant, 2013. p. 93-133.

DREZE, J.; DEBELLE, J. Conceptions de l'Université. Paris Éditions universitaires, 1968. 
DUBET, F. Les inégalités multipliées. La Tour d'Aigues: Les éditions de l'Aube (1re éd. 2001), 2004.

EHRENBERG, A. La fatigue d'être soi. Dépression et société. Paris: Odile Jacob (1re éd. 1998), 2000.

EHRENBERG, A. La société du malaise. Le mental et le social. Paris: Odile Jacob (1re éd. 2010), 2012.

FREITAG, M. Le naufrage de l'Université et autres essais d'épistémologie politique. Montréal et Paris: Nuit blanche/Éditions La découverte, 1995.

FREITAG, M. L'abîme de la liberté. Critique du libéralisme. Montréal: Liber, 2011.

HONNETH, A. La société du mépris. Vers une nouvelle Théorie critique. Paris: Éditions La Découverte, 2006.

JOBERT, R. La fin de l'État tutélaire. Cahiers de la recherche sociologique, v. 24, p. 107-126. 1995.

LENOIR, Y. La socialisation entre éducation thérapeutique et lutte pour la reconnaissance: la question de l'estime de soi. In: LENOIR, Y.; TUPIN, F. (Dir.). Les pratiques enseignantes entre instruire et socialiser. Regards internationaux. Québec: Presses de l’Université Laval, 2012. p. 185-231.

LENOIR, Y. Les médiations au cour des pratiques d'enseignementapprentissage: une approche dialectique. Des fondements à leur actualisation en classe. Éléments pour une théorie de l'intervention éducative. Longueuil: Groupéditions Éditeurs, 2014.

LESSARD, C.; TARDIF, M. La nature et la place d'une formation professionnelle selon les conceptions de l'Université. In: LENOIR, Y.; BOUILLIER-OUDOT, M.-H. (Dir.). Savoirs professionnels et curriculum de formation. Québec: Presses de l'Université Laval, 2006. p. 27-66.

MCPHERSON, C. B. La théorie politique de l'individualisme possessif: de Hobbes à Locke. Trad. M. Fuchs. Paris: Gallimard (1re éd. 1962), 2004.

MARZANO, M. Extension du domaine de la manipulation. De l'entreprise à la vie privée. Paris: Bernard Grasset, 2008.

MEIRIEU, P.; ALTET, M.; LENOIR, Y.; PERRENOUD, P. Qui veut la mort des sciences de l'éducation? Le café pédagogique, v. 13, jan. 2014.

MONZEE, J. Médicaments et performance humaines: thérapie ou dopage? Montréal: Liber, 2010.

READINGS, B. The University in ruins. Cambridge: Havard University Press, 1996.

RENAULT, E. L'expérience de l'injustice. Reconnaissance et clinique de l'injustice. Paris: Éditions La Découverte, 2004.

STIGLITZ, J. E. La grande illusion. Trad. P. Chemla. Paris: Fayard, 2002. 
STIGLITZ, J. E. Un autre monde. Contre le fanatisme du marché. Trad. P. Chemla. Paris: Fayard, 2006.

TUDIVER, N. Universities for sale: Resisting corporate control over canadian higher education. Toronto: James Lorimer and Co, 1999.

TURK, J. L. (Dir.). The corporate campus. Commercialization and the dangers to Canada's colleges and universities. Toronto: James Lorimer and Co, 2000.

WILSHIRE, B. The moral collapse of the university. Professionalism, purity and alienation. Albany, NY: State University of New York Press, 1990.

Texto recebido em 11 de junho de 2016. Texto aprovado em 29 de junho de 2016. 
